\title{
An economic evaluation of a computer-tailored e- learning program to promote smoking cessation counseling guideline adherence among practice nurses
}

Citation for published version (APA):

de Ruijter, D., Hoving, C., Evers, S., Hudales, R., de Vries, H., \& Smit, E. (2019). An economic evaluation of a computer-tailored e-learning program to promote smoking cessation counseling guideline adherence among practice nurses. Patient Education and Counseling, 102(10), 1802-1811.

https://doi.org/10.1016/j.pec.2019.07.015

Document status and date:

Published: 01/10/2019

DOI:

10.1016/j.pec.2019.07.015

Document Version:

Publisher's PDF, also known as Version of record

Document license:

Taverne

Please check the document version of this publication:

- A submitted manuscript is the version of the article upon submission and before peer-review. There can be important differences between the submitted version and the official published version of record. People interested in the research are advised to contact the author for the final version of the publication, or visit the DOI to the publisher's website.

- The final author version and the galley proof are versions of the publication after peer review.

- The final published version features the final layout of the paper including the volume, issue and page numbers.

Link to publication

\footnotetext{
General rights rights.

- You may freely distribute the URL identifying the publication in the public portal. please follow below link for the End User Agreement:

www.umlib.nl/taverne-license

Take down policy

If you believe that this document breaches copyright please contact us at:

repository@maastrichtuniversity.nl

providing details and we will investigate your claim.
}

Copyright and moral rights for the publications made accessible in the public portal are retained by the authors and/or other copyright owners and it is a condition of accessing publications that users recognise and abide by the legal requirements associated with these

- Users may download and print one copy of any publication from the public portal for the purpose of private study or research.

- You may not further distribute the material or use it for any profit-making activity or commercial gain

If the publication is distributed under the terms of Article 25fa of the Dutch Copyright Act, indicated by the "Taverne" license above, 


\title{
An economic evaluation of a computer-tailored e-learning program to promote smoking cessation counseling guideline adherence among practice nurses
}

\author{
Dennis de Ruijter ${ }^{\mathrm{a}, *}$, Ciska Hoving ${ }^{\mathrm{a}}$, Silvia Evers ${ }^{\mathrm{b}, \mathrm{c}}$, Raesita Hudales ${ }^{\mathrm{a}}$, Hein de Vries ${ }^{\mathrm{a}}$, \\ Eline Smit ${ }^{\mathrm{d}}$ \\ a Department of Health Promotion, Maastricht University, P.O. Box 616, 6200 MD, Maastricht, the Netherlands

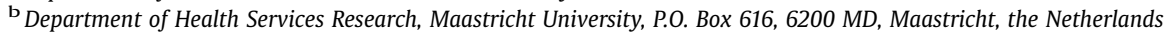 \\ ' Centre of Economic Evaluation, Trimbos Institute, National Institute of Mental Health and Addiction, P.O. Box 725, 3500 AS, Utrecht, the Netherlands \\ d Department of Communication Science, University of Amsterdam, P.O. Box 15791, 1001 NG Amsterdam, the Netherlands
}

\section{A R T I C L E I N F O}

\section{Article history:}

Received 25 February 2019

Received in revised form 25 June 2019

Accepted 13 July 2019

\section{Keywords:}

Economic evaluation

E-learning

Tailoring

Practice nurses

Smoking cessation

Evidence-Based guideline

Guideline adherence

General practice

\begin{abstract}
A B S T R A C T
Objective: To conduct an economic evaluation of a tailored e-learning program, which successfully improved practice nurses' smoking cessation guideline adherence.

Methods: The economic evaluation was embedded in a randomized controlled trial, in which 269 practice nurses recruited 388 smoking patients. Cost-effectiveness was assessed using guideline adherence as effect measure on practice nurse level, and continued smoking abstinence on patient level. Cost-utility was assessed on patient level, using patients' Quality Adjusted Life Years (QALYs) as effect measure. Results: The e-learning program was likely to be cost-effective on practice nurse level, as adherence to an additional guideline step cost $€ 1,586$. On patient level, cost-effectiveness was slightly likely after six months (cost per additional quitter: $€ 7,126$ ), but not after twelve months. The cost-utility analysis revealed slight cost-effectiveness (cost per QALY gained: $€ 18,431$ ) on patient level.

Conclusion: Providing practice nurses with a tailored e-learning program is cost-effective to improve their smoking cessation counseling. Though, cost-effectiveness on patient level was not found after twelve months, potentially resulting from smoking relapse.

Practice implications: Widespread implementation of the e-learning program can improve the quality of smoking cessation care in general practice. Strategies to prevent patients' smoking relapse should be further explored to improve patients' long-term abstinence.
\end{abstract}

(C) 2019 Elsevier B.V. All rights reserved.

\section{Introduction}

Smoking cessation interventions in primary care, such as individual counseling by healthcare professionals (HCPs) in general practice, can effectively increase smokers' quit rates [1]. In the Netherlands, $72 \%$ of smokers visited their general practice in 2016, indicating the potential reach of smoking cessation interventions in this setting [2]. Smoking cessation counseling in general practice is nowadays predominantly provided by trained practice nurses (PNs) [3], applying evidence-based counseling guidelines [4]. These highly educated nurses are employed in $88 \%$ of Dutch general practices and are involved in smoking cessation

\footnotetext{
* Corresponding author at: Maastricht University. P.O. Box 616, 6200 MD, Maastricht, the Netherlands.

E-mail address: d.deruijter@maastrichtuniversity.nl (D. de Ruijter).
}

counseling as part of their responsibilities regarding chronic patient care and lifestyle counseling [5,6]. PNs often take over these tasks from their general practitioner. A systematic review demonstrated that PNs had equal or better outcomes regarding patient satisfaction and quality of care compared to general practitioners, against equal or less associated costs [7]. Also, in the Netherlands PN-led care proved to be comparable to general practitioner-led care both in general [8] and concerning smoking cessation counseling specifically [9], illustrating the potential of PN-led care to be cost saving.

Thus, we know that PNs can reach many smokers in Dutch general practice [2] and that their smoking cessation counseling can potentially be cost saving [8,9]. Nevertheless, previous studies showed that PNs do not systematically adhere to all smoking cessation counseling steps [10-12]. This means PN-led counseling is not yet adequately implemented in practice, which will lower the potential (cost-)effectiveness of their smoking 
cessation care [13]. It is therefore important to support PNs to reach optimal guideline adherence, yet this requires both time and money as PNs need additional training to implement smoking cessation counseling according to the evidence-based guideline [14]. Previously, studies testing counseling support interventions (i.e. web-based or face-to-face training) for HCPs have demonstrated that their smoking cessation counseling improved, as smokers more often received adequate and complete smoking cessation support from their HCP [15-17]. However, as such a counseling support intervention was not yet available for PNs, we developed a novel computer-tailored e-learning program for PNs to support them to optimally implement the national smoking cessation guideline [18].

The content of this e-learning program was based on PNs' needs for individually relevant, easy-to-use web-based counseling support, and incorporates PNs' preferences regarding program design and content [10]. The program offers webbased counseling support in a relatively inexpensive and highly flexible way to a large group of PNs. The program's online availability ensures it can be consulted whenever PNs require and desire it. Program content is tailored to socio-cognitive factors, previously found to be associated with PN guideline adherence [11], to create a personally relevant support tool for each PN [18]. A randomized controlled trial (RCT) demonstrated that access to the e-learning program successfully improved guideline adherence among experienced PNs [19]. Yet, next to establishing the program's effectiveness, evidence regarding the cost-effectiveness is important to inform decision-making concerning care-related policy and resource allocation; this enables policy makers to compare costs and effects of different interventions with current practice and to subsequently make an informed decision on implementation of these interventions [20]. Although some studies have conducted economic evaluations of face-to-face interventions to train HCPs in smoking cessation counseling [21,22], none have investigated the costeffectiveness of web-based counseling support for HCPs.

Therefore, the present paper aims to describe the results from a trial-based economic evaluation of the e-learning program from a societal perspective on two levels, the PN and patient level. On PN level, we will determine the cost-effectiveness of the e-learning program to improve PNs' smoking cessation counseling. We hypothesize that improved counseling by PNs will positively affect patients' smoking cessation education and quality of patient care. Hence, we will assess indirect program effects on counseled patients' smoking cessation rates and quality of life to also evaluate the cost-effectiveness and cost-utility of the e-learning program on patient level.

\section{Methods}

\subsection{Study design}

This economic evaluation was embedded in a RCT testing the effectiveness of the e-learning program among Dutch PNs and their smoking patients with a twelve-month follow-up period [19]. In this RCT only PNs in the intervention group had access to the computer-tailored content of the e-learning program for six months, whereas PNs in the control group were instructed to provide smoking cessation care as usual. A detailed description of the trial's design and the e-learning program's content is published elsewhere [18]. Evaluation by the Medical Ethics Committee Atrium-Orbis-Zuyd (14-N-17) revealed that no medical ethical clearance for this study was needed according to the rules of the Medical Research Involving Human Subjects Act (WMO). The study is registered with the Dutch Trial Register (NTR4436).

\subsection{Participants and procedure}

\subsubsection{Practice nurses}

PNs enrolled in the RCT between January-June 2016. Eligible PNs were engaged in smoking cessation counseling in Dutch general practice, had Internet access and a working email account, and were sufficiently proficient in Dutch. After providing online informed consent and completing the baseline questionnaire, 269 PNs were randomized at respondent level to the intervention or control group of the trial through a computer software randomization device [19].

\subsubsection{Smoking patients}

During the six-month trial, PNs were instructed to engage in counseling with smoking patients and recruit those patients for trial participation (Fig. 1). Eligible patients were smokers of 18 years or older, had Internet access and a working email account, and were sufficiently proficient in Dutch. Interested patients could leave their email address with their PN and were subsequently invited via email to fill out the baseline questionnaire.

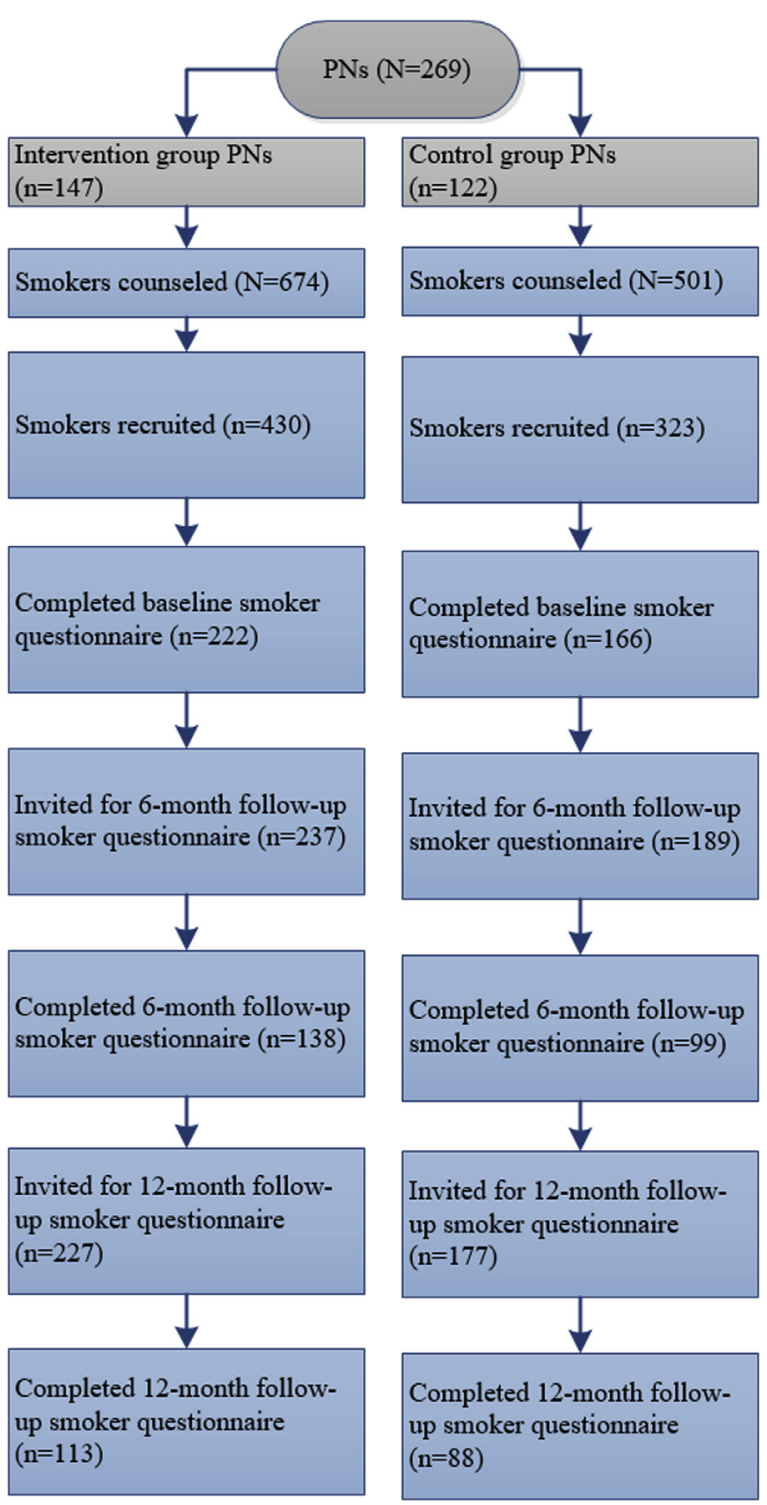

Fig. 1. Flow of smoking patients counseled by PNs in the intervention and control group. 


\subsection{The e-learning program}

The computer-tailored e-learning program consisted of 1) five e-learning modules with tailored advice, a forum, and smoking cessation counseling materials; and 2) three general modules containing project information, frequently asked questions about the trial, and a counseling checklist to self-report application of guideline steps. The content of the e-learning modules was based on a behavior change framework, the I-Change Model [23], and previously developed, effective computer-tailored behavior change interventions [24-27]. Advice was tailored to individual PNs' questionnaire answers, addressing demographic characteristics (e.g. gender), pre-motivational factors (e.g. knowledge), motivational factors (e.g. self-efficacy), post-motivational factors (e.g. coping planning), intention (to use a smoking cessation guideline), and behavior (i.e. self-reported application of smoking cessation guideline steps). During the six-month trial, intervention group PNs $(\mathrm{N}=147)$ had full access to the e-learning program, whereas control group PNs only had access to the three general modules [18].

\subsection{Economic evaluation}

This economic evaluation compared costs and effects concerning the computer-tailored e-learning program for PNs (i.e. intervention group with full program access) with costs and effects concerning regular PN-led smoking cessation counseling (i.e. control group with access to general program modules only). The economic evaluation was conducted from a societal perspective, meaning that we also included costs and effects from outside the healthcare setting [28]. This study was applied on PN and patient level, and was based on national [28] and international guidelines [29], following five steps (Table 1): 1) identification of costs and effects, 2) measurement of costs and effects, 3 ) valuation of costs and effects, 4) calculation of a cost-effectiveness ratio, and 5) analysis of uncertainty [20].

\subsubsection{Identification of costs and effects}

\subsubsection{Identification on $P N$ level}

On PN level, intervention and time costs were considered relevant. Intervention costs related to delivery of the e-learning program (e.g. hosting of the website and e-learning program). Program development costs and research-related costs were excluded, as these would not be required for program implementation. Time costs included time lost due to program engagement and counseling smoking patients.
The primary outcome measure used in the cost-effectiveness analysis (CEA) was PNs' evidence-based smoking cessation guideline adherence. A change in quality of life was not expected among PNs, since PNs' counseling is rather related to their patients' health status. Hence, a cost-utility analysis (CUA) was not conducted on PN level.

\subsubsection{Identification on patient level}

On patient level, healthcare costs and patient costs were considered relevant. Healthcare costs related to patients' healthcare usage during the trial, including contact with HCPs, hospital admissions, prescribed and over-the-counter medication, and other types of care. Patient costs included travel costs and costs associated with time lost by participating in PN-led smoking cessation consultations.

The primary outcome measure was self-reported smoking abstinence for the CEA, and quality of life expressed in quality adjusted life years (QALYs) [18] for the CUA. As self-reported measures of smoking status have shown to be valid and noninvasive, no other methods for measuring smoking status were used in this study [30].

\subsubsection{Measurement of costs and effects}

\subsubsection{Measurement on PN level}

Costs for hosting the website ( $€ 58.35$ for six months) and the computer-tailored e-learning program ( $€ 208$ for six months $+a$ one-off user license of $€ 2,350$ ) were retrieved from providers. PNs' program engagement (i.e. number and duration of visits) was assessed through log data. PNs' time spent on counseling was assessed using the reported duration of each consultation via completed counseling checklists.

Guideline adherence was self-reported by PNs after every consultation with a smoking patient using the counseling checklist. Adherence $(\mathrm{y} / \mathrm{n})$ was assessed concerning the following guideline steps: 1) advising to quit smoking, 2) assessing smoking profile and history, 3) assessing quit motivation, 4) increasing motivation, 5) assessing barriers to quitting, 6) discussing barriers, 7) informing about cessation aids, 8) making a quit plan and setting a quit date, and 9) arranging follow-up after the quit date [18].

\subsubsection{Measurement on patient level}

Healthcare costs were assessed using a six-month retrospective online questionnaire, based on a previously developed questionnaire [31], at six-month and twelve-month follow-up. Patients reported the number of contacts with: PN, general practitioner, inpatient and/or outpatient specialist, mental HCP.

Table 1

Five steps in conducting an economic evaluation [20]

1. Identification of costs and effects

2. Measurement of costs and effects

3. Valuation of costs and effects

4. Calculation of a costeffectiveness ratio

5. Analysis of uncertainty
All relevant costs and effects associated with the intervention and target behavior are identified.

Costs are usually assessed via a retrospective cost questionnaire. Effects are often assessed via questionnaires. For measuring quality of life it is recommended to use instruments that measure generic rather than disease-specific quality of life, to promote comparability with interventions targeting other health behaviors.

Costs are preferably valued according to reference prices listed in a country-specific manual for conducting economic evaluations. Costs should be indexed to the same year to ensure prices are comparable. When valuing effects on quality of life it is required to calculate utility scores, representing preferences regarding a set of health states, which are used to calculate QALYs. Costs and effects are combined into an ICER concerning behavior-specific effects, or an ICUR regarding QALYs. These ratios represent the difference in costs between intervention and control group divided by the difference in effects between these groups. As both costs and effects of a new intervention are often higher, country-specific cut-off points have been established for the WTP per QALY gained, which vary according to disease severity.

Sampling uncertainty can be dealt with by conducting bootstrap analyses, thereby drawing multiple random samples (often thousands) from the original data set each with their own ICER/ICUR. These are used to estimate an intervention's probability to be preferred over the control treatment. Other types of uncertainty can be dealt with by conducting sensitivity analyses to test the robustness of the results under different assumptions. 
occupational physician, lifestyle coach, social worker, pharmacist, and alternative medicine professional. Patients indicated the number and duration of hospital admissions, and reported the frequency and duration of other care (i.e. home-care, informal care, rehabilitation, physical therapy, dental care). Patients reported the dose, duration and frequency of prescribed smoking cessation medication (i.e. Varenicline, Bupropion, Nortriptyline, Paroxetine) and over-the-counter nicotine replacement therapy (i.e. nicotine patch, gum, spray) used, if any. Other types of medication (e.g. antibiotics, pain killers) were also reported, when used. Patients' travel and time costs were based on the number and duration of their PN-led consultations (i.e. number of checklists completed).

Continuous smoking abstinence was assessed after six and twelve months by asking if patients had refrained from smoking $(0=$ no; 1 =yes $)$ since baseline [32]. Quality of life was assessed through the ICECAP questionnaire [33] to assess patients' quality of life as their general capability regarding five attributes: attachment, stability, autonomy, achievement and enjoyment $(1=$ not capable; 2 =a little capable; 3 = quite capable; 4 = fully capable).

\subsubsection{Valuation of costs and effects}

Cost valuation was based on the guideline for conducting economic evaluation studies in healthcare [28]. Standardized costs prizes were used when available. Otherwise, costs were estimated based on real costs (e.g. average cost price based on HCPs' real consultation prices) or tariffs, while selecting the lowest price in case of uncertainty.

\subsubsection{Valuation on $P N$ level}

Intervention costs were calculated to be $€ 2,616.35$ (website $€ 58.35$, e-learning program $€ 2,558$ ). Program engagement was valued using productivity costs for paid work (€34.75/hour [28]). Time costs concerning counseling were valued with cost prices for either a short (20 min or less; $€ 9.07$ ) or long consultation (over $20 \mathrm{~min}$; €18.33) [28], resulting in accumulated counseling costs per PN.

Guideline adherence was computed by combining all checklist data of the same smoker into a single score, between 0 (no step was adhered to) and 9 (all steps were adhered to). A mean adherence score was computed to summarize a PN's adherence across separate smokers.

\subsubsection{Valuation on patient level}

Healthcare costs were indexed to represent cost prices in 2016 (consumer price index $=100.32$ ). As reference prices in the guideline were from the year 2014 (consumer price index $=99.40$ ), cost prices were multiplied by $100.32 / 99.40$ (price index 2016/ price index 2014) [34]. The lowest dose and/or lowest price was chosen in case of uncertainty about the dose and/or price, whereas uncertainty about the duration of use was resolved by retrieving the standard treatment protocol from the Dutch medication and pharmacotherapy database (i.e. www.farmacotherapeutischkompas.nl [35]). For prescribed medication, first-use prescription charges $(€ 14.50)$ were added to the cost price or repeated-use prescription charges $(€ 7.25)$ when medication was also listed at another measurement. For prescribed medication the 'price per pill' was calculated, based on information from the Dutch database on medication costs (i.e. www.medicijnkosten.nl [36]). Concerning over-the-counter (smoking cessation) medication, the 'price per pack' was calculated [36].

To calculate travel costs, patients' PN-led consultations were multiplied with the average travel distance to a Dutch general practice $(1.1 \mathrm{~km})$, parking fees ( $€ 3 /$ visit) and transportation costs ( $€ 0.19 /$ kilometer) [28]. To calculate time costs, the duration of consultations was valued using productivity costs for unpaid work (€14/hour [28]).

Smoking abstinence was valued to represent patients' continued abstinence ( 1 =abstinent, $0=$ relapsed $)$. ICECAP scores on each attribute were translated into a tariff score [33], resulting in an overall, accumulated utility value for capability, ranging from -0.001 (no capability) to 1 (full capability). For example, an ICECAP state of ' $44144^{\prime}$ represents someone who is not capable to have autonomy but fully capable concerning the other attributes (i.e. utility score of 0.818) [33]. QALYs were computed by taking the average of ICECAP utility scores at baseline and both follow-up measurements, representing a gain or loss in number of QALYs per year [28]. Gaining 0.9 QALYs either means gaining one year of near perfect capability or gaining 0.9 years of perfect capability.

\subsubsection{Calculation of a cost-effectiveness ratio}

On PN level, all costs on PN and patient level, and PNs' guideline adherence were included to calculate the ICER, according to the formula: (costs $s_{\text {intervention group }}-$ costs $_{\text {control group) / (guideline }}$ adherence $_{\text {intervention group }}$ - guideline adherence $_{\text {control group). On }}$ patient level, also all costs were included. For the ICER, continued smoking abstinence after six or twelve months was included and for the ICUR, QALYs based on ICECAP utilities were included.

\subsubsection{Uncertainty analyses}

As cost distributions tend to be skewed, bootstrapping analyses (1,000 samples) were conducted to address uncertainty around estimated costs and to compute means and confidence intervals for costs. Bootstrapping (5,000 samples) was also conducted to address sample uncertainty when calculating an ICER/ICUR, resulting in the creation of costeffectiveness planes (CEP) and cost-effectiveness acceptability curves (CEAC). A CEP is a scatter plot expressing incremental costs on one axis and incremental outcomes on the other axis, showing the probability of the intervention being 1 ) cost-saving and more effective (dominant), 2) cost-saving and less effective, 3 ) cost-increasing and more effective, and 4) cost-increasing and less effective (dominated). The CEAC is used to explore the probability of the intervention being cost-effective for a range of willingness to pay (WTP) thresholds [37]. Concerning the ICUR, cost-effectiveness was determined by comparing the ICUR to the Dutch WTP threshold, which is $€ 20,000 / Q A L Y$ for preventive interventions [38].

Sensitivity analyses were conducted to test the robustness of the results. On PN level, the CEA was repeated while making a distinction between program users (i.e. at least one module visit,

Table 2

Baseline characteristics of PNs in the intervention and control group.

\begin{tabular}{|c|c|c|c|c|c|}
\hline Baseline PN characteristics & Total sample $(\mathrm{N}=269)$ & Intervention group $(\mathrm{N}=147)$ & Control group $(\mathrm{N}=122)$ & Chi square/t-statistic & $\mathrm{P}$ \\
\hline Age in years, mean (SD) & $47.3(9.5)$ & $48.0(9.6)$ & $46.5(9.4)$ & -1.345 & .18 \\
\hline Gender: female, (\%) & $263(97.8 \%)$ & $143(97.3 \%)$ & $120(98.4 \%)$ & .358 & .55 \\
\hline Working hours, mean (SD) & $25.7(7.4)$ & $25.7(7.5)$ & $25.7(7.4)$ & -.007 & .99 \\
\hline Counseling experience in years, mean (SD) & $5.6(3.7)$ & $5.5(3.6)$ & $5.8(3.8)$ & -.602 & .55 \\
\hline Employed in > 1 practice $(\%)$ & $127(47.2 \%)$ & $70(47.6 \%)$ & $57(46.7 \%)$ & .022 & .88 \\
\hline
\end{tabular}


based on the e-learning program's log data) and non-users, instead of comparing intervention and control group PNs. On patient level, the CUA was repeated from a health-related quality of life perspective (i.e. based on EuroQol [39] utilities), instead of a capability perspective based on ICECAP utilities.

\subsection{Data analyses}

Missing data concerning costs and ICECAP scores were replaced by mean imputation, based on available data from the previous and next assessment. In case multiple assessments were missing, data were replaced using the last observation carried forward method. Data concerning smoking abstinence were analyzed according to the complete-case principle. In secondary analyses, missing data on smoking abstinence were replaced using a conservative scenario, meaning that patient drop-outs were considered to be smoking.

Baseline comparability of PNs and patients was tested with Chisquare tests and independent-samples t-tests. These tests were also used to assess differences in effects between patients counseled by intervention and control group PNs. On PN level, a difference in effect was assessed with the independent-samples t-test.

Table 3

Baseline characteristics of patients counseled by intervention and control group PNs.

\begin{tabular}{|c|c|c|c|c|c|}
\hline Baseline patient characteristics & Total sample $(\mathrm{N}=388)$ & Intervention group $(\mathrm{N}=222)$ & Control group $(\mathrm{N}=166)$ & Chi square/t-statistic & $\mathrm{P}$ \\
\hline Age in years, mean (SD) & $50.4(12.2)$ & $50.6(12.4)$ & $50.1(11.9)$ & -.410 & .68 \\
\hline Gender: female (\%) & $226(58.2 \%)$ & $136(61.3 \%)$ & $90(54.2 \%)$ & 1.938 & .16 \\
\hline $\operatorname{SES}(\%)^{\mathrm{a}}$ & & & & .246 & .97 \\
\hline - low & $14(3.6 \%)$ & $8(3.6 \%)$ & $6(3.6 \%)$ & & \\
\hline - medium low & $118(30.4 \%)$ & $67(30.2 \%)$ & $51(30.7 \%)$ & & \\
\hline - medium high & $136(35.1 \%)$ & $80(36.0 \%)$ & $56(33.7 \%)$ & & \\
\hline - high & $120(30.9 \%)$ & 67 (30.2\%) & $53(31.9 \%)$ & & \\
\hline Quit intention (1-7), mean (SD) & $6.5(0.6)$ & $6.5(0.6)$ & $6.5(0.6)$ & -.358 & .72 \\
\hline FTND $(0-10)$, mean $(S D)^{b}$ & $5.2(2.0)$ & $5.2(2.0)$ & $5.3(2.1)$ & .239 & .81 \\
\hline ICECAP utility, mean (SD) & $0.85(0.1)$ & $0.85(0.1)$ & $0.84(0.1)$ & -1.295 & .20 \\
\hline Healthcare costs in euros, mean $(S D)^{c}$ & $430(1,358)$ & $474(1,580)$ & $372(987)$ & -.730 & .47 \\
\hline
\end{tabular}

a SES categories are based on a combination of an individual's level of education and the profession of the household's main breadwinner [32].

b FTND refers to the Fagerström test for nicotine dependence.

c Costs during the prior six months.

Table 4

Costs and effects on PN level until 12-month follow-up.

\begin{tabular}{|c|c|c|c|c|}
\hline & Intervention group $(\mathrm{N}=117)$ & Control group $(\mathrm{N}=94)$ & & \\
\hline Costs & & & $95 \% \mathrm{CI}$ & \\
\hline Intervention costs in euros, mean (SD) ${ }^{1}$ & $57(4)$ & $6(0.9)$ & 43 & 60 \\
\hline Time costs in euros, mean (SD) ${ }^{1}$ & $163(12)$ & $155(14)$ & -29 & 44 \\
\hline Effects & & & $\mathrm{t}$ & $\mathrm{P}$ \\
\hline Guideline adherence (0-9), mean (SD) & $7.7(1)$ & $7.4(2)$ & -1.704 & .09 \\
\hline
\end{tabular}

1 Mean costs based on complete baseline sample $(\mathrm{N}=269)$.

Table 5

Costs and effects on patient level at six- and twelve-month follow up.

\begin{tabular}{|c|c|c|c|c|}
\hline Six-month follow-up & Intervention group $(\mathrm{N}=138)$ & Control group $(\mathrm{N}=99)$ & & \\
\hline Costs & & & 95\% CI cost-difference & \\
\hline Healthcare costs in euros, mean (SD) ${ }^{\mathrm{a}}$ & $690(83)$ & $535(49)$ & -29 & 357 \\
\hline Patient costs in euros, mean (SD) & $22(0.8)$ & $23(0.9)$ & -3 & 1 \\
\hline Effects & & & $\mathrm{F} / \mathrm{t}$ & $\mathrm{P}$ \\
\hline Continued abstinence (\%) & $60(43.5 \%)$ & $38(38.4 \%)$ & 0.617 & .43 \\
\hline Quit intention (1-7), mean (SD) & $6.3(1)$ & $6.2(1)$ & -0.192 & .85 \\
\hline FTND $(0-10)$, mean $(S D)^{b}$ & $3.1(2)$ & $4.1(2)$ & 2.769 & .01 \\
\hline ICECAP utility, mean (SD) & $0.85(0.2)$ & $0.85(0.1)$ & 0.333 & .74 \\
\hline Twelve-month follow-up & Intervention group $(\mathrm{N}=113)$ & Control group $(\mathrm{N}=88)$ & & \\
\hline Costs & & & 95\% CI cost-difference & \\
\hline Healthcare costs in euros, mean (SD) ${ }^{\mathrm{a}}$ & 390 (39) & $536(87)$ & -339 & 41 \\
\hline Patient costs in euros, mean $(\mathrm{SD})^{\mathrm{a}, \mathrm{c}}$ & $9(0.4)$ & $10(0.5)$ & -2 & 0 \\
\hline Effects & & & $\mathrm{F} / \mathrm{t}$ & $\mathrm{P}$ \\
\hline Continued abstinence (\%) & $53(46.9 \%)$ & $40(45.5 \%)$ & 0.042 & .84 \\
\hline Quit intention (1-7), mean (SD) & $6.4(1)$ & $6.2(1)$ & -0.989 & .32 \\
\hline FTND $(0-10)$, mean $(S D)^{b}$ & $3.4(2)$ & $3.6(2)$ & 0.463 & .64 \\
\hline ICECAP utility, mean (SD) & $0.87(0.1)$ & $0.84(0.1)$ & -1.522 & .13 \\
\hline
\end{tabular}

a Costs during the prior six months.

b Only patients who smoked at follow-up are included.

c Only patients who had consultations with their PN between six- and twelve month follow-up are included. 
Calculations of the ICER/ICUR and bootstrap analyses were conducted using Microsoft Office Excel 2011. Other analyses were conducted using SPSS 24.0.

\section{Results}

\subsection{Sample characteristics}

PNs' and patients' baseline characteristics are presented in Table 2 and Table 3, including a comparison of characteristics between the intervention and control group. No baseline differences were found between intervention and control group PNs, or between their counseled patients.

\subsection{Annual costs and effects}

On PN level, intervention costs were higher in the intervention group ( $€ 57$ vs. $€ 6$ ) and time costs were comparable between the groups (Table 4). PNs' guideline adherence did not significantly differ between the intervention and control group.

On patient level, a significant difference was found regarding their score on the Fagerström test for nicotine dependence (FTND) at six-month follow-up (3.1 for intervention and 4.1 for control group patients). No differences were found regarding patients' healthcare costs and patient costs, smoking abstinence, quit intention and ICECAP utility scores (Table 5). At 12-month followup, FTND scores no longer differed between intervention and

Table 6

ICERs and bootstrapped results of cost-effectiveness.

\begin{tabular}{|c|c|c|c|c|}
\hline & \multirow[t]{2}{*}{ ICER/ICUR } & \multicolumn{3}{|c|}{ Likelihood cost-effectiveness at } \\
\hline & & $\mathrm{WTP}=€ 10,000$ & $\mathrm{WTP}=€ 20,000$ & $\mathrm{WTP}=€ 50,000$ \\
\hline PN level: societal perspective & $€ 1,585.54$ & $94 \%$ & $96 \%$ & $97 \%$ \\
\hline PN level: program use perspective & $€ 3,588.57$ & $88 \%$ & $94 \%$ & $96 \%$ \\
\hline Patient level: six-month follow-up & $€ 7,126.48$ & $55 \%$ & $64 \%$ & $68 \%$ \\
\hline Patient level: twelve-month follow-up & $€-961.78$ & $25 \%$ & $26 \%$ & $26 \%$ \\
\hline Patient level: ICECAP & $€ 18,431.16$ & $37 \%$ & $53 \%$ & $67 \%$ \\
\hline Patient level: EuroQol & $€ 33,589.46$ & $30 \%$ & $41 \%$ & $54 \%$ \\
\hline
\end{tabular}

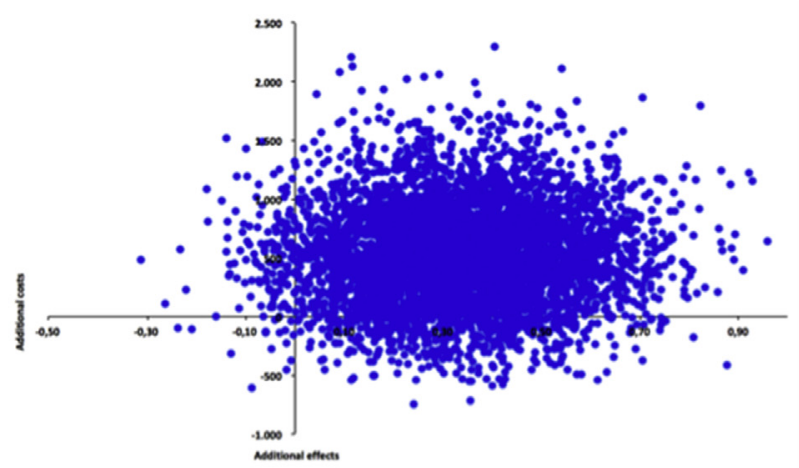

A) CEP on PN level, societal perspective

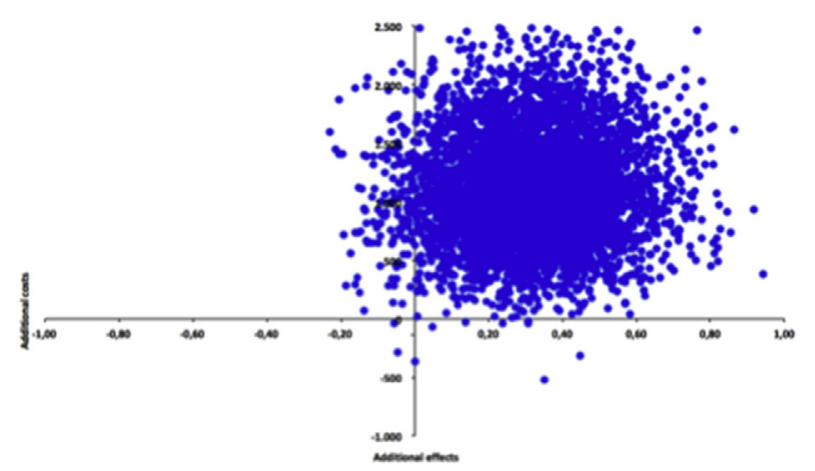

C) CEP on PN level, program use perspective
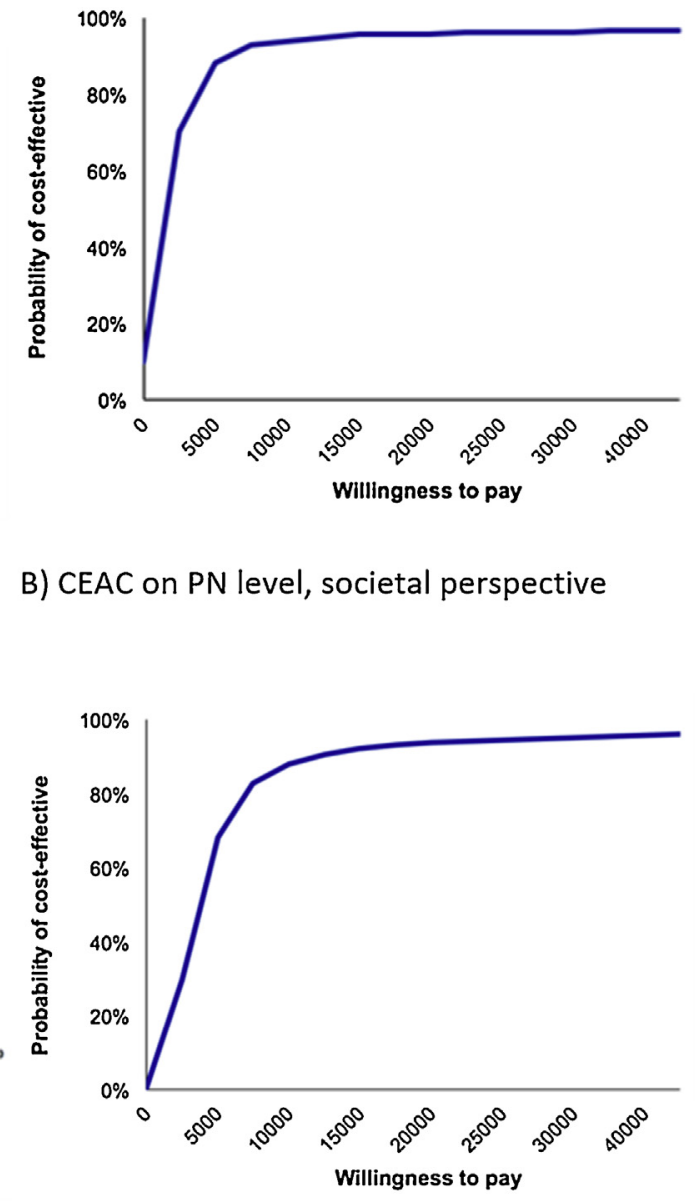

B) CEAC on PN level, societal perspective

D) CEAC on PN level, program use perspective

Fig. 2. Cost-effectiveness planes (left) and corresponding CEACs (right) on PN level with guideline adherence as outcome measure. 
control group patients. Healthcare and patient costs, smoking abstinence, quit intention and ICECAP utility also did not differ after twelve months (Table 5).

\subsection{Cost-effectiveness analyses}

On PN level, the CEA demonstrates that in comparison to the control group, $€ 1,585.54$ has to be paid in the intervention group for each additional guideline step that is on average adhered to by PNs. From a program use perspective (i.e. non-use vs. at least single use), the CEA shows that costs are $€ 3,588.57$ for each additional guideline step that is on average adhered to by PNs (Table 6). The CEAC shows that, concerning both perspectives, the program is already highly likely to be cost-effective at a WTP threshold of $€ 10,000$ (Fig. 2).

On patient level, the CEA demonstrates that in comparison to the control group, $€ 7,126.48$ has to be paid in the intervention group for each additional patient being abstinent at six-month follow-up and that the intervention group is dominated by the control group at twelve-month follow-up (Table 6). The CEAC shows that it is only slightly likely that the program is costeffective after six months and not likely to be cost-effective after twelve months (Fig. 3). Results from secondary conservative analyses (i.e. 'missing = smoking' assumption), showed similar results: costs for each additional patient being abstinent at sixmonth follow-up are $€ 11,886.17$, and the intervention group is dominated by the control group at twelve-month follow-up.

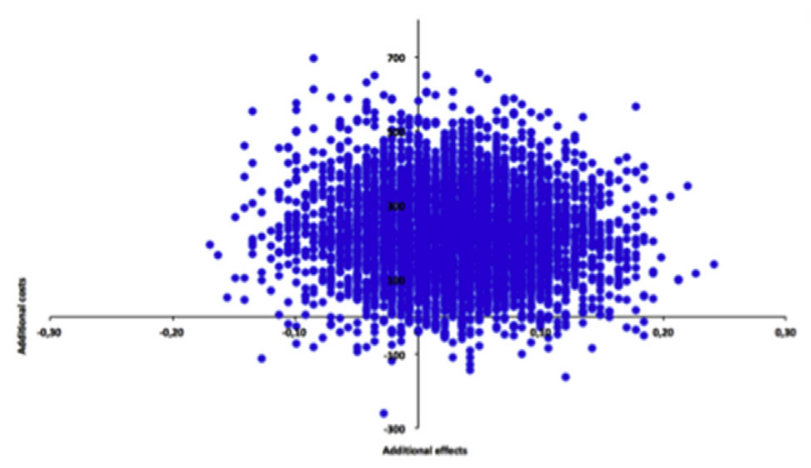

A) CEP on patient level, six-month follow-up

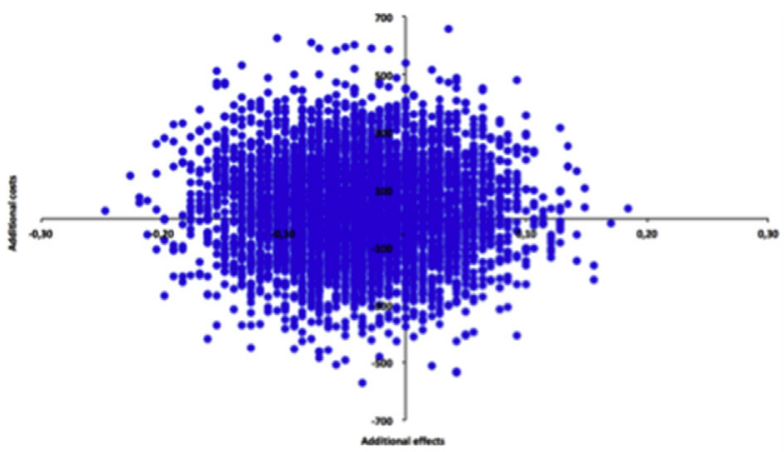

C) CEP on patient level, 12-month follow-up

\subsection{Cost-utility analyses}

The CUA conducted from a capability perspective (i.e. with ICECAP utility scores) demonstrates that in comparison to the control group, costs per QALY gained are $€ 18,431.16$ in the intervention group. The CUA, from a health-related quality of life perspective (i.e. with EuroQol utility scores), demonstrates that these costs per QALY gained are $€ 33,589.46$ (Table 6). The CEAC shows that at the Dutch WTP threshold of $€ 20,000$ [38] the intervention is 53\% likely to be cost-effective regarding ICECAP utilities and 41\% likely concerning EuroQol utilities (Fig. 4).

\section{Discussion and conclusion}

\subsection{Discussion}

On PN level, the CEA demonstrated that the e-learning program was likely to be cost-effective to improve PNs' guideline adherence. This indicates that the additional effects outweigh the additional costs associated with providing intervention group PNs with access to the e-learning program. Intervention costs were higher for intervention group PNs as control group PNs did not have access to the full e-learning program. Time costs (i.e. costs associated with program use and counseling) were similar between both groups; additional analysis revealed that time costs associated with program use were higher among intervention group PNs (€40 vs. $€ 6)$, as they engaged more with the e-learning program. As time

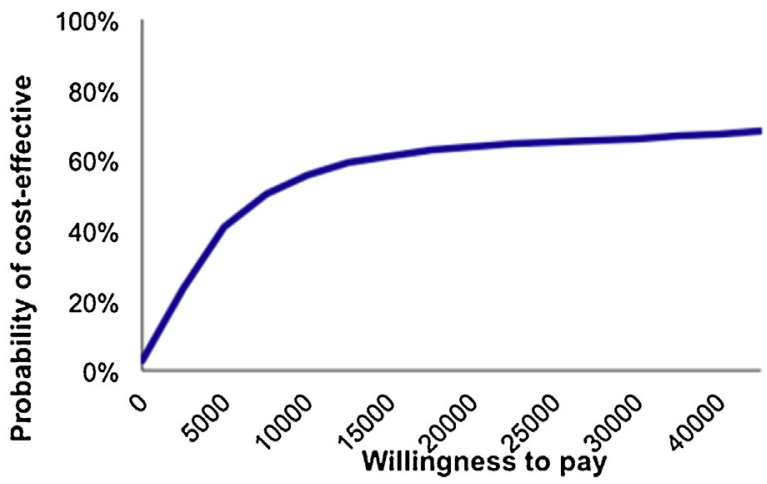

B) CEAC on patient level, six-month follow-up

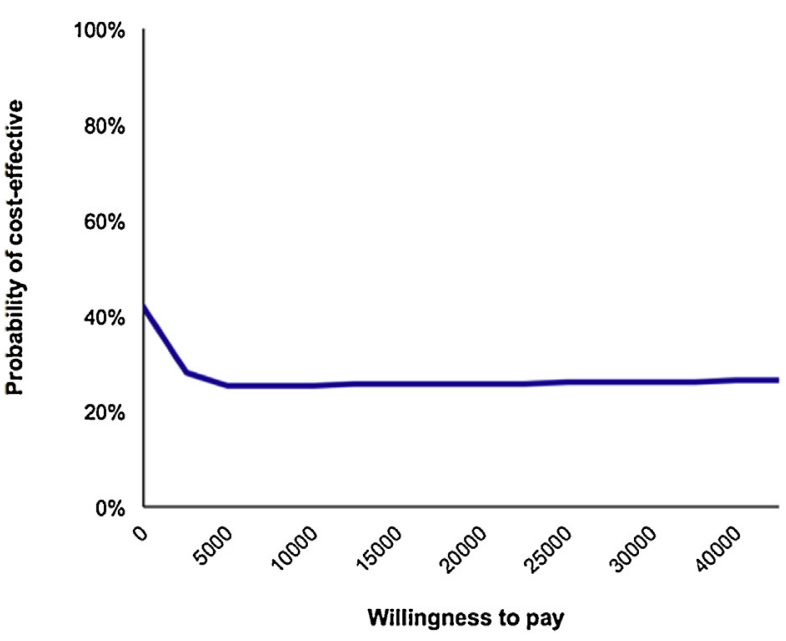

D) CEAC on patient level, 12-month follow-up

Fig. 3. Cost-effectiveness planes (left) and corresponding CEACs (right) on patient level with smoking abstinence as outcome measure. 


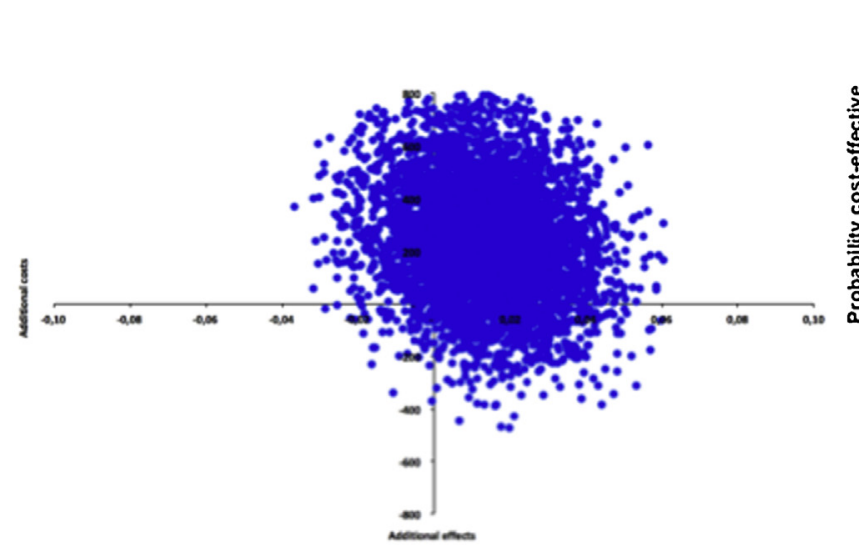

A) CEP on patient level, ICECAP utilities

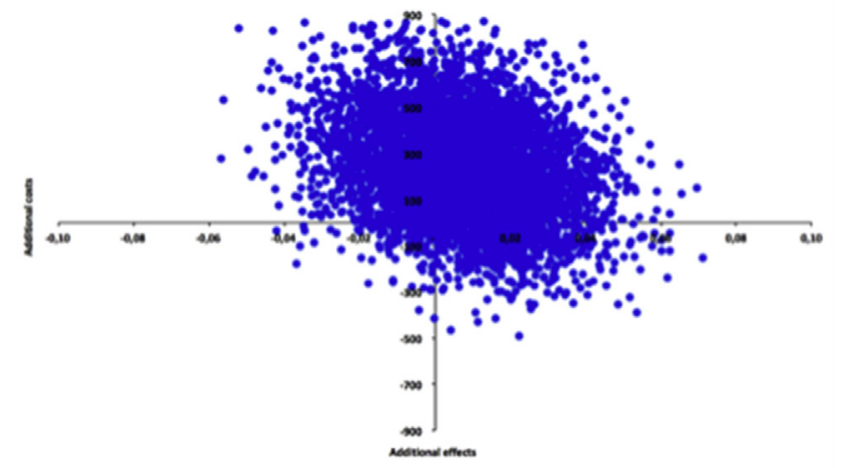

C) CEP on patient level, EuroQol utilities

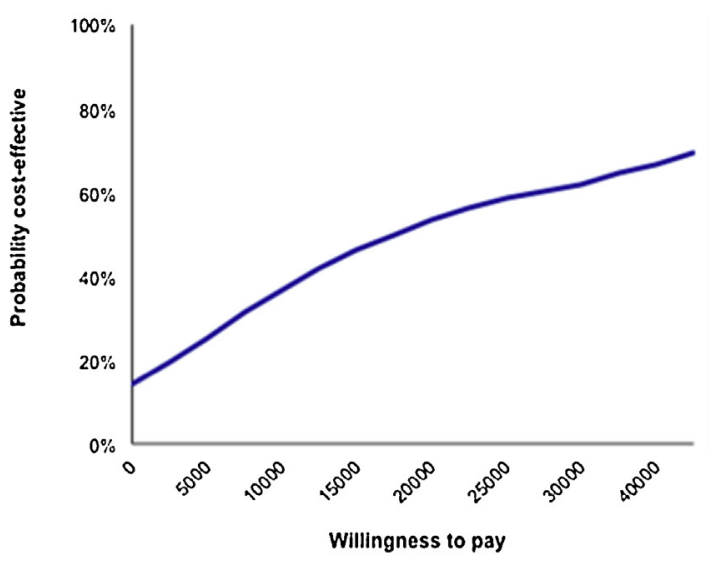

B) CEAC on patient level, ICECAP utilities

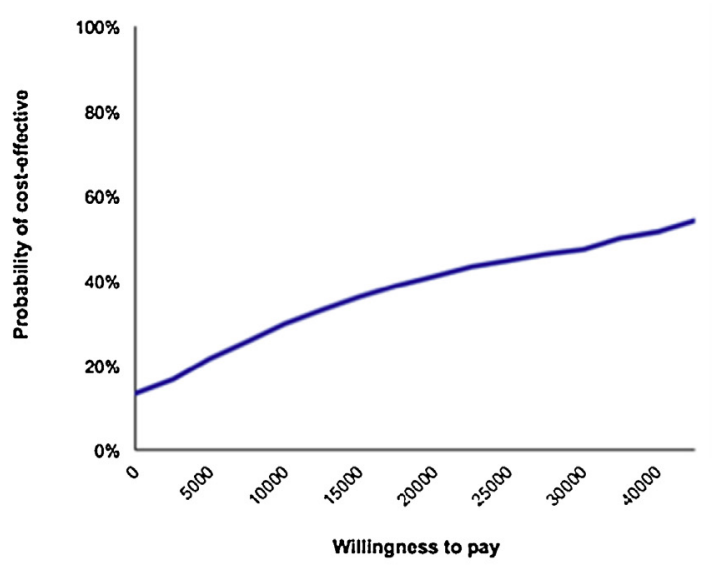

D) CEAC on patient level, EuroQol utilities

Fig. 4. Cost-effectiveness planes (left) and corresponding CEACs (right) concerning utilities at smoker level.

costs associated with counseling did not differ between the groups, and additional analysis found no significant differences in the number and duration of consultations, the small difference in PNs' guideline adherence likely results from an improvement in the quality of counseling, rather than its quantity. The CEA on PN level revealed that adherence to each additional guideline step was associated with incremental costs of $€ 1,586$. Although information is currently lacking about society's willingness to pay for effects such as guideline adherence and smoking abstinence (i.e. only WTP thresholds per QALY gained are available [38]), our bootstrapped results were consistent across several WTP thresholds. Hence, providing PNs with an e-learning program seems worth the investment to achieve an improvement in smoking cessation counseling. As the quality of PN-led care is known to be comparable to general practitioner-led care $[8,9]$ and has the potential to be cost-saving [7], providing PNs with this e-learning program will improve chances that PN-led care will also be costeffective in Dutch general practice. Hence, it is recommended to pursue widespread program use by PNs across the Netherlands. However, as program implementation entails challenges [40-42], systematic implementation research is required to ensure the development of an evidence-based implementation plan. Such a plan should be supported by the program's target group and other relevant stakeholders to develop a practically feasible implementation approach $[43,44]$.
On patient level, no differences in costs and smoking abstinence were found after six and twelve months, although after six months lower FTND scores were found among intervention group patients - an effect that disappeared after twelve months. For patients the e-learning program was only slightly cost-effective after six months, yet not cost-effective after twelve months. This finding was confirmed by CUA using capability-related and health-related quality of life as outcome measures. An explanation for finding no effects on patient level, could be that many patients relapsed back to smoking after making a quit attempt [45]. More specifically, as a result of the e-learning program, intervention group PNs might have been more motivated to engage in counseling with a wider range of smoking patients, including patients that were more nicotine dependent. As nicotine dependence is known to predict quit success [46], these patients first needed to lower their dependence before making a quit attempt, which is supported by our results showing improvement in FTND scores among intervention group patients after six months. As this effect on FTND scores disappeared after twelve months, this could suggest a delayed relapse back to smoking (e.g. as a result of wrongful use of or premature discontinuation of cessation medication) among intervention group patients between six- and twelve-month follow-up. Future research should focus on preventing smoking relapse among patients who are counseled by a PN in general practice. PNs could, for instance, explore possibilities to refer 
patients to complementary smoking relapse interventions [47] in addition to PN-led counseling. PNs could actively refer patients to additional evidence-based, behavioral support focusing on training coping skills $[24,48,49]$ or could recommend additional pharmacotherapeutic support [50,51], known to be effective to prevent smoking relapse. By supporting smokers to additionally use such effective relapse prevention strategies it could be possible to achieve improved abstinence rates that are sustained over a longer time period.

\subsection{Strengths and limitations}

Results from this economic evaluation of our novel e-learning program for PNs can be used by those that formulate health policy to make informed decisions on smoking cessation investments. In line with recent recommendations, an assessment of quality of life from a broader perspective than health-only was used (i.e. capability-related quality of life), enabling comparison of our results with economic evaluations in other domains [52]. Nevertheless, no effects concerning quality of life were found, which could be the result of the twelve-month follow-up period not being long enough to detect changes in patients' quality of life, which is often attributed to patients experiencing withdrawal symptoms after quitting smoking [53]. Also, other recent studies among smoking patients found little or no effects concerning QALYs, measured after similar follow-up periods [31,54]. It is suggested to either extend the period of data collection of trialbased economic evaluations, or to use modelling techniques to predict long-term costs and effects [52].

A limitation of this study was the low number of patients that enrolled in the trial (33\%; 388/1,175) and the high number of patients that dropped out of the trial after enrollment (48\%; 187/ 388). Unfortunately, this seems to be inherent in trials concerning web-based interventions, which often report similar or even worse results [55-57]. Consequently, however, this might have limited the statistical power of our analyses to detect the small differences in patients' smoking abstinence.

\subsection{Conclusions and practice implications}

Providing PNs with a tailored e-learning program to support their adherence to the national smoking cessation guideline can be a cost-effective approach to improve PNs' smoking cessation counseling. National implementation of the e-learning program should be pursued as it can improve the quality of smoking cessation care among a larger population of PNs. Unfortunately, results do not show cost-effectiveness on patient level. Future research should focus on strategies to prevent patients' smoking relapse and to reliably assess long-term costs and effects.

\section{Author contributions}

The co-authors (i.e. $\mathrm{CH}$, HdV \& ES) developed the proposal for the present research. The first author (i.e. DdR) was responsible for conducting and reporting on the research. A research assistant (i.e. $\mathrm{RH}$ ) assisted in data management and analysis and the coauthors (i.e. CH, SE, HdV \& ES) supervised the process and provided feedback. All authors report to have no conflict of interest. We confirm that all personal identifiers have been removed or disguised so the person(s) described are not identifiable and cannot be identified through the details of the story. All authors have approved the final article.

\section{Declaration of Competing Interest}

All authors declare to have no conflict of interests.

\section{Acknowledgements}

We wish to thank all participating practice nurses and patients for their time. This study was funded by a grant from the Dutch Cancer Society (UM2013-6107). The funder was not actively involved in the publication process.

\section{References}

[1] L.F. Stead, P. Koilpillai, T.R. Fanshawe, T. Lancaster, Combined pharmacotherapy and behavioural interventions for smoking cessation, Cochrane Database Syst. Rev. 3 (2016)Cd008286.

[2] L. Springvloet, M. van Laar, Roken Onder Volwassenen: Kerncijfers 2016, Nationaal Expertisecentrum Tabaksontmoediging, Utrecht, 2017.

[3] T. Freund, C. Everett, P. Griffiths, C. Hudon, L. Naccarella, M. Laurant, Skill mix, roles and remuneration in the primary care workforce: Who are the healthcare professionals in the primary care teams across the world? Int. J. Nurs. Stud. 52 (3) (2015) 727-743.

[4] N.H.G. Trimbos-instituut, Richtlijn Behandeling Van Tabaksverslaving En Stoppen Met Roken Ondersteuning Herziening 2016, (2016) .

[5] P.J.M. Heiligers, J. Noordman, J.C. Korevaar, S. Dorsman, L. Hingstman, A.Mv Dulmen, D.Hd. Bakker, Kennisvraag: Praktijkondersteuners in De Huisartspraktijk (POH's), Klaar Voor De Toekomst? NIVEL, Utrecht, 2012, pp. $1-124$.

[6] D. van Hassel, R. Batenburg, L. van der Velden, Praktijkondersteuners (POH's) in Beeld: Aantallen, Kenmerken En Geografische Spreiding in Nederland, NIVEL, Utrecht, 2016.

[7] M. Swan, S. Ferguson, A. Chang, E. Larson, A. Smaldone, Quality of primary care by advanced practice nurses: a systematic review, Int. J. Qual. Health Care: J. Int. Soc. Qual. Health Care / ISQua 27 (5) (2015) 396-404.

[8] A.T. Dierick-van Daele, J.F. Metsemakers, E.W. Derckx, C. Spreeuwenberg, H.J. Vrijhoef, Nurse practitioners substituting for general practitioners: randomized controlled trial, J. Adv. Nurs. 65 (2) (2009) 391-401.

[9] C. van Rossem, M. Spigt, W. Viechtbauer, A.E.M. Lucas, O.C.P. van Schayck, D. Kotz, Effectiveness of intensive practice nurse counselling versus brief general practitioner advice, both combined with varenicline, for smoking cessation: a randomised pragmatic trial in primary care, Addiction (2017).

[10] D. de Ruijter, E.S. Smit, H. de Vries, L. Goossens, C. Hoving, Understanding Dutch practice nurses' adherence to evidence-based smoking cessation guidelines and their needs for web-based adherence support: results from semistructured interviews, BMJ Open 7 (3) (2017)e014154.

[11] D. de Ruijter, E.S. Smit, H. de Vries, C. Hoving, Dutch practice nurses' adherence to evidence-based smoking cessation treatment guidelines, Fam. Pract. (2017).

[12] D. Whitehead, S.B. Zucker, J. Stone, Tobacco cessation education for advanced practice nurses, Nurse Educ. 39 (5) (2014) 252-255.

[13] R.E. Glasgow, E. Lichtenstein, A.C. Marcus, Why don't we see more translation of health promotion research to practice? Rethinking the efficacy-toeffectiveness transition, Am. J. Public Health 93 (8) (2003) 1261-1267.

[14] P. Selby, K. Goncharenko, M. Barker, M. Fahim, V. Timothy, R. Dragonetti, K. Kemper, M. Herie, J.T. Hays, Review and evaluation of online tobacco dependence treatment training programs for health care practitioners, J. Med. Internet Res. 17 (4) (2015) e97.

[15] M. Unrod, M. Smith, B. Spring, J. DePue, W. Redd, G. Winkel, Randomized controlled trial of a computer-based, tailored intervention to increase smoking cessation counseling by primary care physicians, J. Gen. Intern. Med. 22 (4) (2007) 478-484.

[16] M.E. Verbiest, M.R. Crone, M. Scharloo, N.H. Chavannes, V. van der Meer, A.A Kaptein, W.J. Assendelft, One-hour training for general practitioners in reducing the implementation gap of smoking cessation care: a clusterrandomized controlled trial, Nicotine Tob. Res. 16 (1) (2014) 1-10.

[17] T. Asfar, D.J. Lee, B.L. Lam, A.P. Murchison, E.L. Mayro, C. Owsley, G. McGwin, E. W. Gower, D.S. Friedman, J. Saaddine, Evaluation of a Web-Based Training in Smoking Cessation Counseling Targeting U.S. Eye-Care Professionals, Health education \& behavior : the official publication of the Society for Public Health Education, 20171090198117709883.

[18] D. de Ruijter, E.S. Smit, H. de Vries, C. Hoving, Web-based computer-tailoring for practice nurses aimed to improve smoking cessation guideline adherence: a study protocol for a randomized controlled effectiveness trial, Contemp. Clin. Trials 48 (2016) 125-132.

[19] D. de Ruijter, M. Candel, E.S. Smit, H. de Vries, C. Hoving The effectiveness of a computer-tailored E-Learning program for practice nurses to improve their adherence to smoking cessation counseling guidelines: randomized controlled trial, J. Med. Internet Res. 20 (5) (2018) e193.

[20] S. Evers, C. Wolfs, C. Van Heugten, Economische evaluatie van neurospychologische behandeling, in: R. Ponds, C. van Heugten, L. Fasotti, E. Wekking (Eds.), Neuropsychologische Behandeling, Boom Uitgeverij, Amsterdam, 2010.

[21] C. Pinget, E. Martin, J.B. Wasserfallen, J.P. Humair, J. Cornuz, Costeffectiveness analysis of a European primary-care physician training in smoking cessation counseling, European journal of cardiovascular prevention and rehabilitation : official journal of the European Society of Cardiology, Working Groups Epidemiol. Prev. Cardiac Rehabil. Exercise Physiol. 14 (3) (2007) 451-455. 
[22] S.B. Cantor, A.A. Deshmukh, N.S. Luca, G.M. Nogueras-Gonzalez, T. Rajan, A.V. Prokhorov, Cost-effectiveness analysis of smoking-cessation counseling training for physicians and pharmacists, Addict. Behav. 45 (2015) 79-86.

[23] H. de Vries, An integrated approach for understanding health behavior; the IChange model as an example, Psychol. Behav. Sci. Int. J. 2 (2) (2017) 1-4.

[24] I. Elfeddali, C. Bolman, M.J. Candel, R.W. Wiers, H. de Vries, Preventing smoking relapse via Web-based computer-tailored feedback: a randomized controlled trial, J. Med. Internet Res. 14 (4) (2012) e109.

[25] N. Stanczyk, C. Bolman, M. van Adrichem, M. Candel, J. Muris, H. de Vries, Comparison of text and video computer-tailored interventions for smoking cessation: randomized controlled trial, J. Med. Internet Res. 16 (3) (2014) e69.

[26] E.S. Smit, H. de Vries, C. Hoving, Effectiveness of a Web-based multiple tailored smoking cessation program: a randomized controlled trial among Dutch adult smokers, J. Med. Internet Res. 14 (3) (2012) e82.

[27] C. Bolman, S.M. Eggers, L. van Osch, F. Te Poel, M. Candel, H. de Vries, Is action planning helpful for smoking cessation? Assessing the effects of action planning in a web-based computer-tailored intervention, Subst. Use Misuse (2015) 1-12.

[28] L. Hakkaart-van Roijen, N. van der Linden, C. Bouwmans, T. Kanters, S.S. Tan, Kostenhandleiding: Methodologie Van Kostenonderzoek En Referentieprijzen Voor Economische Evaluaties in De Gezondheidszorg, Institute for Medical Technology Assessment, Erasmus Universiteit Rotterdam, Zorginstituut, Nederland, 2016.

[29] D. Husereau, M. Drummond, S. Petrou, C. Carswell, D. Moher, D. Greenberg, F. Augustovski, A.H. Briggs, J. Mauskopf, E. Loder, Consolidated health economic evaluation reporting standards (CHEERS)-explanation and elaboration: a report of the ISPOR health economic evaluation publication guidelines good reporting practices task force, Value Health 16 (2) (2013) 231-250.

[30] S.L. Wong, M. Shields, S. Leatherdale, E. Malaison, D. Hammond, Assessment of validity of self-reported smoking status, Health Rep. 23 (1) (2012) 47-53.

[31] E.S. Smit, S.M. Evers, H. de Vries, C. Hoving, Cost-effectiveness and cost-utility of Internet-based computer tailoring for smoking cessation, J. Med. Internet Res. 15 (3) (2013) e57.

[32] A.N. Mudde, M.C. Willemsen, S. Kremers, H. de Vries, Meetinstrumenten voor onderzoek naar roken en stoppen met roken, Dutch Expert Center for Tobacco Control, The Hague (2006).

[33] H. Al-Janabi, T.N. Flynn, J. Coast, Development of a self-report measure of capability wellbeing for adults: the ICECAP-A, Quality of life research : an international journal of quality of life aspects of treatment, Care Rehabil. 21 (1) (2012) 167-176

[34] CentraalBureau voor de Statistiek, Consumentenprijzen; Prijsindex $2015=100$, Den Haag/Heerlen, (2017) . (Accessed 12 July 2017) http://statline.cbs.nl/Statweb/ publication $/ ? \mathrm{DM}=\mathrm{SLNL} \& \mathrm{PA}=83131$ ned $\& \mathrm{D} 1=0-6 \& \mathrm{D} 2=0 \& \mathrm{D} 3=(1-39)-1 \& \mathrm{VW}=\mathrm{T}$.

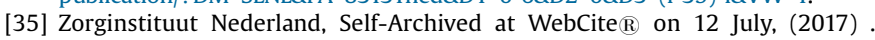
[http://www.webcitation.org/74RJrBc7v] www. farmacotherapeutischkompas.nl.

[36] Zorginstituut Nederland, Self-Archived at WebCite $\mathbb{R}$ on 12 July, (2017) . [http://www.webcitation.org/74RJuJ7uR] www.medicijnkosten.nl.

[37] E. Fenwick, B.J. O’Brien, A. Briggs, Cost-effectiveness acceptability curves - facts, fallacies and frequently asked questions, Health Econ. 13 (5) (2004) 405-415.

[38] Raad voor de Volksgezondheid en Zorg, Zinnige En Duurzame Zorg: Transparante Keuzen in De Zorg Voor Een Houdbaar Zorgstelsel, Raad voor de Volksgezondheid en zorg: Zoetermeer, 2006.

[39] M.M. Versteegh, K.M. Vermeulen, S.M.A.A. Evers, G.A. de Wit, R. Prenger, E.A. Stolk, Dutch tariff for the five-level version of EQ-5D, Value Health 19 (4) (2016) 343-352.
[40] I. van de Glind, M. Heinen, W. Geense, I. Mesters, M. Wensing, T. van Achterberg, Making the connection-factors influencing implementation of evidence supported and non-evaluated lifestyle interventions in healthcare: a multiple case study, Health Educ. Res. 30 (4) (2015) 521-541.

[41] V. Joseph, R.M. West, D. Shickle, J. Keen, S. Clamp, Key challenges in the development and implementation of telehealth projects, J. Telemed. Telecare 17 (2011).

[42] B. Ahmed, T. Dannhauser, N. Philip, A systematic review of reviews to identify key research opportunities within the field of eHealth implementation, J. Telemed. Telecare (2018) 1357633x18768601.

[43] M. van Limburg, J. Wentzel, R. Sanderman, L. van Gemert-Pijnen, Business modeling to implement an eHealth portal for infection control: a reflection on Co-creation with stakeholders, JMIR Res. Protoc. 4 (3) (2015) e104.

[44] J.E. van Gemert-Pijnen, N. Nijland, M. van Limburg, H.C. Ossebaard, S.M. Kelders, G. Eysenbach, E.R. Seydel, A holistic framework to improve the uptake and impact of eHealth technologies, J. Med. Internet Res. 13 (4) (2011) e111.

[45] G.A. Marlatt, D. Donovan M, Relapse Prevention-Maintenance Strategies in the Treatment of Addictive Behaviour, 2nd ed., Guildford Press, New York, 2009.

[46] E. Vangeli, J. Stapleton, E.S. Smit, R. Borland, R. West, Predictors of attempts to stop smoking and their success in adult general population samples: a systematic review, Addiction 106 (12) (2011) 2110-2121.

[47] S.E. Collins, K. Witkiewitz, M. Kirouac, G.A. Marlatt, Preventing relapse following smoking cessation, Curr. Cardiovasc. Risk Rep. 4 (6) (2010) 421-428.

[48] M. Unrod, V.N. Simmons, S.K. Sutton, K.M. Cummings, P. Celestino, B.M. Craig, J H. Lee, L.R. Meltzer, T.H. Brandon, Relapse-Prevention Booklets as an Adjunct to a Tobacco Quitline: A Randomized Controlled Effectiveness Trial, Nicotine Tob. Res. 18 (3) (2016) 298-305.

[49] T.N. Chirikos, T.A. Herzog, C.D. Meade, M.S. Webb, T.H. Brandon, Costeffectiveness analysis of a complementary health intervention: the case of smoking relapse prevention, Int. J. Technol. Assess. Health Care 20 (4) (2004) 475-480.

[50] T. Coleman, S. Agboola, J. Leonardi-Bee, M. Taylor, A. McEwen, A. McNeill, Relapse prevention in UK Stop Smoking Services: current practice, systematic reviews of effectiveness and cost-effectiveness analysis, Health Technol. Assess. 14 (49) (2010) 1-152 iii-iv.

[51] S. Agboola, A. McNeill, T. Coleman, J.L. Bee, A systematic review of the effectiveness of smoking relapse prevention interventions for abstinent smokers, Addiction 105 (8) (2010) 1362-1380.

[52] E.S. Smit, H. de Vries, E.J.M. Oberjé, S.M.A.A. Evers, Easier said than done: overcoming challenges in the economic evaluation of internet-based lifestyle interventions, Eur. Health Psychologist 17 (1) (2015) 39-44.

[53] S. Shiffman, C. Patten, C. Gwaltney, J. Paty, M. Gnys, J. Kassel, M. Hickcox, A. Waters, M. Balabanis, Natural history of nicotine withdrawal, Addiction 101 (12) (2006) 1822-1832.

[54] N. Berndt, C. Bolman, L. Lechner, W. Max, A. Mudde, H. de Vries, S. Evers, Economic evaluation of a telephone- and face-to-face-delivered counseling intervention for smoking cessation in patients with coronary heart disease, Eur. J. Health Econ. 17 (3) (2016) 269-285.

[55] G.G. Bennett, R.E. Glasgow, The delivery of public health interventions via the Internet: actualizing their potential, Annu. Rev. Public Health 30 (2009) $273-292$.

[56] G. Eysenbach, The law of attrition, J. Med. Internet Res. 7 (1) (2005) e11.

[57] L.F. Kohl, R. Crutzen, N.K. de Vries, Online prevention aimed at lifestyle behaviors: a systematic review of reviews, J. Med. Internet Res. 15 (7) (2013) e146. 